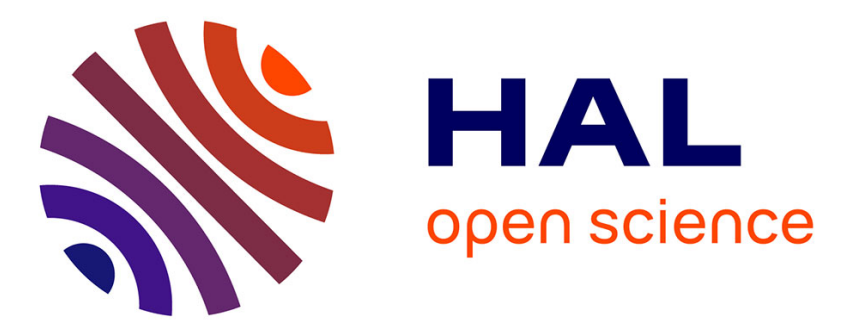

\title{
Investigating magnetic proximity effects at ferrite/Pt interfaces
}

\author{
M. Collet, R. Mattana, J.-B. Moussy, K. Ollefs, S. Collin, C. Deranlot, A. \\ Anane, V. Cros, F. Petroff, F. Wilhelm, et al.
}

\section{- To cite this version:}

M. Collet, R. Mattana, J.-B. Moussy, K. Ollefs, S. Collin, et al.. Investigating magnetic proximity effects at ferrite/Pt interfaces. Applied Physics Letters, 2017, 111 (20), pp.202401 - 202402. 10.1063/1.4987145 . hal-01666597

\section{HAL Id: hal-01666597 https://hal.science/hal-01666597}

Submitted on 18 Dec 2017

HAL is a multi-disciplinary open access archive for the deposit and dissemination of scientific research documents, whether they are published or not. The documents may come from teaching and research institutions in France or abroad, or from public or private research centers.
L'archive ouverte pluridisciplinaire HAL, est destinée au dépôt et à la diffusion de documents scientifiques de niveau recherche, publiés ou non, émanant des établissements d'enseignement et de recherche français ou étrangers, des laboratoires publics ou privés. 


\title{
Investigating magnetic proximity effects at ferrite/Pt interfaces
}

\author{
M. Collet, ${ }^{1}$ R. Mattana, ${ }^{1}$ J.-B. Moussy, ${ }^{2}$ K. Ollefs, ${ }^{3}$ S. Collin,,${ }^{1}$ C. Deranlot,${ }^{1}$ A. Anane,${ }^{1}$ \\ V. Cros, ${ }^{1}$ F. Petroff, ${ }^{1}$ F. Wilhelm, ${ }^{3}$ and A. Rogalev ${ }^{3}$ \\ ${ }^{1}$ Unité Mixte de Physique CNRS/Thales, CNRS, Thales, Univ. Paris-Sud, Université Paris-Saclay, \\ 91767 Palaiseau, France \\ ${ }^{2}$ SPEC, CEA, CNRS, Université Paris-Saclay, CEA Saclay, 91191 Gif-sur-Yvette, France \\ ${ }^{3}$ European Synchrotron Radiation Facility (ESRF), CS40220, 71, Avenue des Martyrs, 38043 Grenoble Cedex 9 , \\ France
}

(Received 8 June 2017; accepted 28 October 2017; published online 13 November 2017)

\begin{abstract}
Spintronic devices based on pure spin currents have drawn a lot of attention during the last few years for low energy device design. One approach to generate pure spin currents is to combine a metallic or insulating ferromagnetic layer with a non-magnetic metallic layer with a large spin-orbit coupling. A recent controversy has arisen in the possible role of magnetic proximity effects at ferromagnetic/ non-magnetic interfaces, which can hamper the understanding of pure spin current generation mechanisms. While magnetic proximity effects have been frequently observed at ferromagnetic metal/nonmagnetic interfaces, there are only a few studies on ferromagnetic insulator/non-magnetic interfaces. Regarding the use of ferromagnetic insulators, the focus has been mainly on yttrium iron garnet (YIG). However, investigation of induced magnetic moments at YIG/Pt interfaces has engendered contradictory results. Here, we propose to study insulating ferrites for which electronic and magnetic properties can be modulated. Magnetic proximity effects have been investigated at $\mathrm{MnFe}_{2} \mathrm{O}_{4} / \mathrm{Pt}$, $\mathrm{CoFe}_{2} \mathrm{O}_{4} / \mathrm{Pt}$, and $\mathrm{NiFe}_{2} \mathrm{O}_{4} / \mathrm{Pt}$ interfaces by X-ray circular magnetic dichroism (XMCD) measurements at the $\mathrm{Pt}_{3}$ edge. Although hybridization with Pt seems to be different among the ferrites, we do not detect any XMCD signal as the signature of an induced magnetism in Pt. We have then studied the $\mathrm{Fe}_{3} \mathrm{O}_{4}$ ferrite below and above the Verwey transition temperature. No XMCD signal has been measured in the insulating or conducting phase of $\mathrm{Fe}_{3} \mathrm{O}_{4}$. This suggests that the absence of magnetic proximity effects at ferrite/Pt interfaces is not linked to the insulating character or not of the ferrites. Published by AIP Publishing. https://doi.org/10.1063/1.4987145
\end{abstract}

Generating a pure spin current without charge flow is a hot topic in spintronics for potential low energy consumption devices. Pure spin currents can be generated by the spin Seebeck effect (SSE) ${ }^{1,2}$ or spin Hall effect (SHE) or detected by inverse spin Hall effects (ISHEs). ${ }^{3}$ Conventional systems to produce pure spin currents are ferromagnetic/non-ferromagnetic (FM/ $\mathrm{N}-\mathrm{FM}$ ) bilayers where the ferromagnetic (FM) thin layers are metallic or insulating and the non-ferromagnetic (N-FM) layer is a metal with a large spin-orbit coupling. In almost all experiments, a thin Pt layer is used. While Pt offers the advantage of a large spin-orbit coupling, magnetic proximity effects at the FM/Pt interface might occur and thus hamper the detection of the pure spin current by electrical measurements. ${ }^{4}$ The main reason is that in such a case, in addition to ISHE and SSE effects, the induced magnetic moments in Pt thin films shall also lead to a transverse voltage contribution due to anomalous Hall and/or Nernst effects.

While magnetic proximity effects at ferromagnetic metal/non-ferromagnetic metal (FMM/N-FM) interfaces have been widely investigated, ${ }^{5-8}$ experiments on the ferromagnetic insulator (FMI)/N-FM interface are sparse. Clear $\mathrm{X}$-ray circular magnetic dichroism (XMCD) signals have been observed in FMM/N-FM (where FMM is typically Co, $\mathrm{Fe}$, or $\mathrm{Ni}$ and $\mathrm{NMN}$ is $\mathrm{Pd}, \mathrm{Pt}, \mathrm{Au}$, etc.), but there are few and disparate results on FMI/Pt interfaces. Recent experiments on $\mathrm{Y}_{3} \mathrm{Fe}_{5} \mathrm{O}_{12} / \mathrm{Pt}$ bilayers have been performed but have led to contradictory results ${ }^{9,10}$ and are still debated. ${ }^{11}$ In yttrium iron garnet (YIG)/Pd systems, in which the signal from the gadolinium gallium garnet substrate less affects the X-ray absorption spectra at the L edges of the heavy elements, no XMCD signal has been detected at the Pd energy edge. ${ }^{12}$ Here, in order to provide a clearer insight, we report on magnetic proximity effect studies at ferrite/Pt interfaces. Ferrites such as $\mathrm{XFe}_{2} \mathrm{O}_{4}(\mathrm{X}=\mathrm{Mn}, \mathrm{Co}$, and $\mathrm{Ni})$ are insulating ferrimagnets whose magnetic and electronic properties can be varied in a controllable way. It is anticipated that they shall be complementary to YIG as promising systems to generate pure spin currents in spintronic devices ${ }^{13-17}$ and even increase the accessible frequency range toward higher values. Their interesting advantage is that by changing the divalent cation ( $\mathrm{Mn}, \mathrm{Co}$, and $\mathrm{Ni}$ ), the magnetic moment, energy gap, and exchange energy can be tailored. Our objective is thus to investigate the magnetic proximity effects at ferrite/Pt interfaces by X-ray absorption near edge spectroscopy (XANES) and X-ray circular magnetic dichroism $(\mathrm{XMCD})$ measurements at the $\mathrm{Pt} \mathrm{L}_{3}$ edge. $\mathrm{XMCD}$ is the most direct experimental technique to probe induced magnetic moments since quantitative information such as spin and orbital moments can be obtained using magneto-optical sum rules. The ferrites studied are $\mathrm{MnFe}_{2} \mathrm{O}_{4}, \mathrm{CoFe}_{2} \mathrm{O}_{4}$, and $\mathrm{NiFe}_{2} \mathrm{O}_{4}$.

$\mathrm{MnFe}_{2} \mathrm{O}_{4}(111), \mathrm{CoFe}_{2} \mathrm{O}_{4}(111)$, and $\mathrm{NiFe}_{2} \mathrm{O}_{4}(111)$ thin films $(\sim 15-40 \mathrm{~nm})$ have been grown by molecular beam epitaxy on sapphire $\left[\alpha-\mathrm{Al}_{2} \mathrm{O}_{3}(00001)\right]$ substrates. Details on growth conditions and sample characterization can be found elsewhere. ${ }^{18}$ In the present study, we have performed conventional characterization to study the structural and magnetic properties by reflection high-energy electron diffraction 
during the growth, in-situ X-ray photoemission spectroscopy, and magnetometry. In particular, it allows us to determine the $\mathrm{X} / \mathrm{Fe}$ ratio as well as the valence of the $3 d$ elements. Advanced characterization has been performed previously such as X-ray absorption spectroscopy and XMCD at $3 d$ elements ( $\mathrm{Mn}, \mathrm{Co}, \mathrm{Ni}$, and $\mathrm{Fe}$ ) $\mathrm{L}_{23}$ edges in order to properly identify the spinel structure of different thin films. Cobalt and nickel ferrites have mainly an inverse spinel structure, ${ }^{18}$ whereas manganese ferrite has a normal spinel structure. ${ }^{19}$ As induced magnetism is expected to occur at the interface and spread over a few atomic layers only, ${ }^{5}$ we have investigated the potential induced magnetism in $2 \mathrm{~nm}$ thick $\mathrm{Pt}$ films grown ex-situ by sputtering deposition. The surface roughness of $\mathrm{Pt}$ thin films has been measured by AFM, showing a root mean square roughness of $\sim 0.1 \mathrm{~nm}$. A Co $(10 \mathrm{~nm}) / 2 \mathrm{~nm}$ Pt reference sample was also investigated for comparison. $\mathrm{Co} / \mathrm{Pt}$ is a wellknown system for which a clear XMCD signal at $\mathrm{Pt}_{23}$ edges has already been observed. ${ }^{8}$

XANES and XMCD experiments have been performed at the ESRF ID12 beamline. Since the $\mathrm{L}_{3}$ edge XMCD signal is expected to be larger than at the $\mathrm{L}_{2}$ edge, we focus in this study on $\mathrm{Pt} \mathrm{L}_{3}$ edges. Measurements have been performed at both $10 \mathrm{~K}$ and $290 \mathrm{~K}$. Grazing incidence magnetic fields up to $3 \mathrm{~T}$ have been applied in order to saturate the ferrite's magnetization (see supplementary material). Total fluorescence yield mode detection was used. To measure XMCD, the photon helicity (circular left and right) and the magnetic field were systematically flipped. ${ }^{20}$

Normalized XANES $\mathrm{L}_{3} \mathrm{Pt}$ edge spectra recorded at $290 \mathrm{~K}$ for the three different ferrites and the Co/Pt reference sample are shown in Fig. 1. Although Pt XANES spectra of ferrite samples present the same fine structure as those of the $\mathrm{Co} / \mathrm{Pt}$ reference sample, indicating similar crystallinity, we observe slight differences in white line intensity, suggesting different electronic structures. In particular, $\mathrm{MnFe}_{2} \mathrm{O}_{4} / \mathrm{Pt}$ has a higher white line (WL) intensity. In comparison, the WL intensity of a metallic Pt foil is less than $1.3 .^{21}$ A WL intensity larger than 1.3 is usually associated with oxidation of $\mathrm{Pt}$; for example, a $\mathrm{PtO}_{1.6}$ compound has a WL intensity larger than 2. ${ }^{22}$ Moreover, it has been observed, for example, in $\mathrm{Pt}$

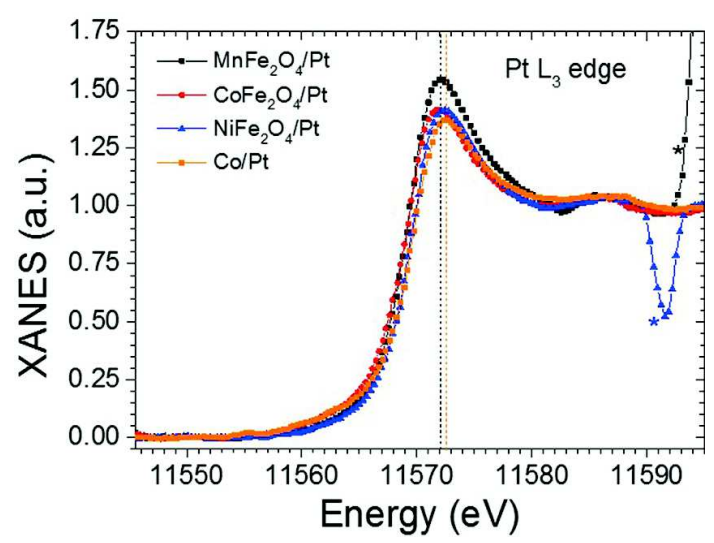

FIG. 1. Normalized $\mathrm{Pt} \mathrm{L}_{3}$ edge XANES spectra recorded at $290 \mathrm{~K}$ for $\mathrm{MnFe}_{2} \mathrm{O}_{4} / \mathrm{Pt}$ (black), $\mathrm{CoFe}_{2} \mathrm{O}_{4} / \mathrm{Pt}$ (red), and $\mathrm{NiFe}_{2} \mathrm{O}_{4} / \mathrm{Pt}$ (blue) samples. Spectra of the $\mathrm{Co} / \mathrm{Pt}$ reference sample (orange) are also shown for comparison. Asterisks point out diffraction peaks. Black and orange dashed lines indicate the maximum of XANES intensity for the $\mathrm{MnFe}_{2} \mathrm{O}_{4} / \mathrm{Pt}$ and $\mathrm{Co} / \mathrm{Pt}$ samples highlighting the energy shift of the white line (WL). based catalysis studies that Pt oxidation usually induces a shift of the white line to higher energy (see, for instance, Refs. 23 and 24). Note, however, that in the case of $\mathrm{MnFe}_{2} \mathrm{O}_{4} / \mathrm{Pt}$, we rather observe a shift to lower energy $(\sim 0.6 \mathrm{eV})$. It has been shown in granular $\mathrm{Co} / \mathrm{Pt}$ multilayers that Pt XANES spectra can be modified by hybridization at the $\mathrm{Co} / \mathrm{Pt}$ interface. ${ }^{25}$ An increase in the WL intensity as the one observed for $\mathrm{MnFe}_{2} \mathrm{O}_{4} / \mathrm{Pt}$ means that the $\mathrm{Pt} 5 d$ band is less filled as a possible consequence of a charge transfer from Pt to $\mathrm{MnFe}_{2} \mathrm{O}_{4}$. This hypothesis would also explain the shift towards lower energies of the WL due to a modification of the Pt Fermi level. For $\mathrm{CoFe}_{2} \mathrm{O}_{4}$, we observe a similar WL energy shift but without an increase in its intensity. The stronger difference observed for $\mathrm{MnFe}_{2} \mathrm{O}_{4}$ could be explained by the fact that it has a smaller energy gap $(0.08 \mathrm{eV}) .^{26}$ On the other hand, $\mathrm{NiFe}_{2} \mathrm{O}_{4}$ which has the largest theoretical energy gap $(0.98 \mathrm{eV})$ has a spectrum closer to the $\mathrm{Co} / \mathrm{Pt}$ reference sample. This could reflect the fact that the hybridization mechanism between ferrite/Pt and $\mathrm{Co} / \mathrm{Pt}$ is certainly different. Localized orbitals for ferrites and localized and delocalized bands for Co could be involved in the hybridization. Thus, these XANES measurements reveal different behavior between ferrites, suggesting a different hybridization at ferrite/Pt interfaces.

As for the proximity effect, we now discuss the XMCD measurements. In Fig. 2(a), we present the XMCD signals at the $\mathrm{Pt} \mathrm{L}_{3}$ edge obtained at $290 \mathrm{~K}$ for the three different ferrites and the $\mathrm{Co} / \mathrm{Pt}$ reference sample. Whereas we observe a clear XMCD signal for $\mathrm{Co} / \mathrm{Pt}$, we do not observe any indication of induced magnetic moments for the ferrites/Pt samples. In Fig. 2(b), we plot XMCD spectra at $10 \mathrm{~K}$ for the three ferrites and together with the $\mathrm{Co} / \mathrm{Pt}$ reference sample. Similar conclusion without any XMCD signal is obtained at room temperature, which allows to us rule out the presence of an interfacial compound with a magnetic transition at low temperature. The absence of magnetic proximity effects in our ferrite/Pt samples is in agreement with XMCD or X-ray resonant magnetic reflectivity measurements performed on the $\mathrm{CoFe}_{2} \mathrm{O}_{4} / \mathrm{Pt}$ (Ref. 27) or $\mathrm{NiFe}_{2} \mathrm{O}_{4} / \mathrm{Pt}$ (Ref. 28) bilayer. However, Amamou et al. have recently observed anisotropic magnetoresistance effects in the $\mathrm{CoFe}_{2} \mathrm{O}_{4} / \mathrm{Pt}$ bilayer, suggesting the magnetic proximity effect. ${ }^{29}$ In Fig. 2(c), we plot XANES and XMCD spectra at $\mathrm{Pt}_{2,3}$ edges for the $\mathrm{Co} / \mathrm{Pt}$ reference sample. By applying magneto-optical sum rules ${ }^{30,31}$ using the method developed for Pt layers, ${ }^{32}$ we deduce spin and orbital moments of $0.197 \mu_{\mathrm{B}} /$ atom and $0.042 \mu_{\mathrm{B}}$ /atom. With the XMCD noise level in ferrite/Pt samples being about 50 times lower than the XMCD signal in the $\mathrm{Co} / \mathrm{Pt}$ sample, we can estimate that if any residual induced magnetic moment takes place, it should be at most about $5 \times 10^{-3} \mu_{\mathrm{B}} / \mathrm{Pt}$ which is close to the magnetic moment of paramagnetic Pt foils at 2 $\mathrm{T}\left[\sim 2.2 \times 10^{-3} \mu_{\mathrm{B}} / \mathrm{Pt}\right.$ (Ref. 21) .

These experiments show that magnetic proximity effects between the investigated ferrites and Pt do not occur (or are too weak to be detected). We have then investigated $\mathrm{Fe}_{3} \mathrm{O}_{4} /$ Pt bilayers. This system offers the advantage that $\mathrm{Fe}_{3} \mathrm{O}_{4}$ (magnetite) thin films are well-known ferromagnetic oxides which have the particularity to exhibit the Verwey transition. ${ }^{33}$ Hence, possible induced magnetic moments can be investigated below and above the metal-insulator transition. We have performed XANES and XMCD measurements 

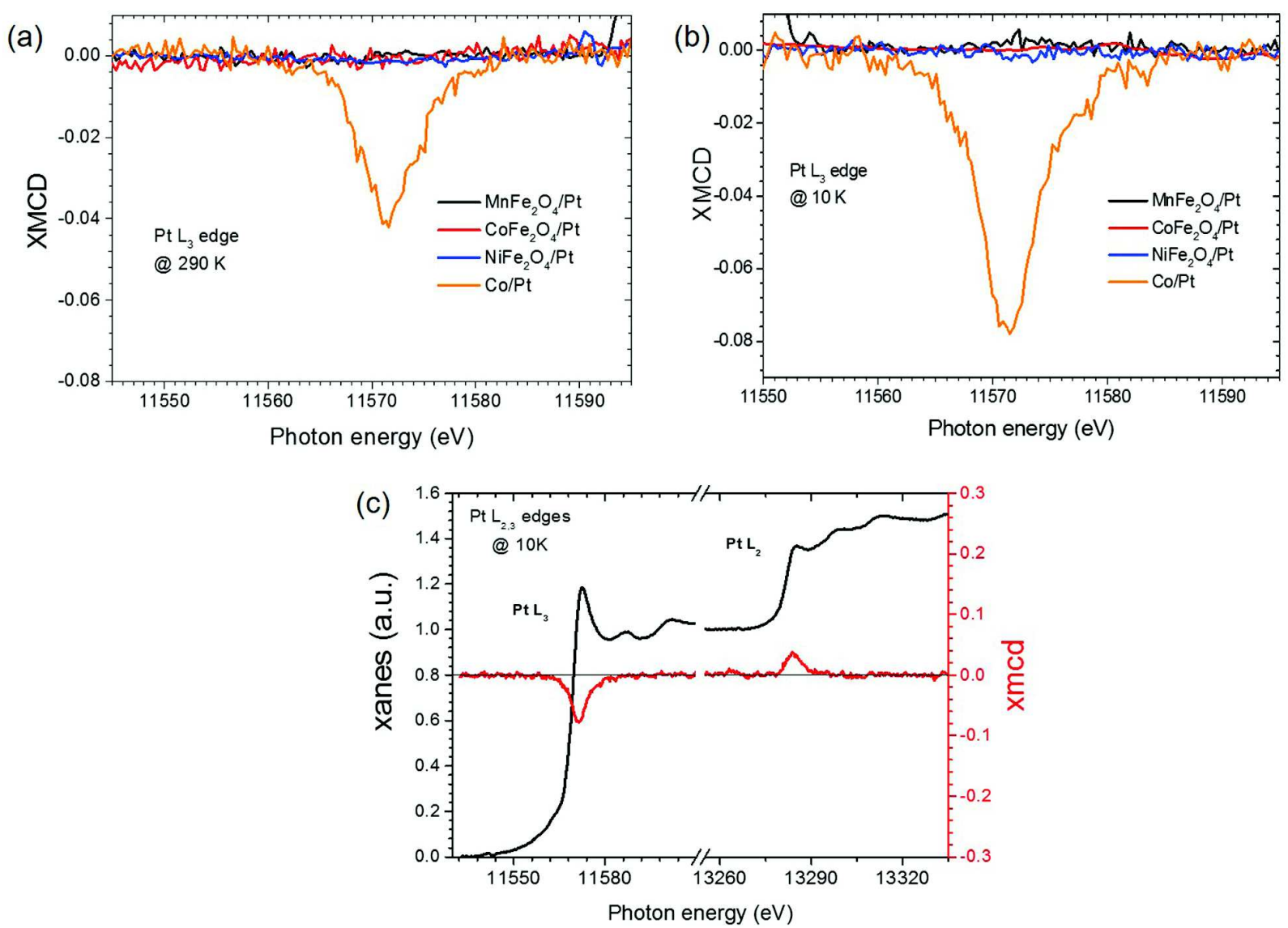

FIG. 2. $\mathrm{Pt} \mathrm{L}_{3}$ edge XMCD spectra recorded at $290 \mathrm{~K}$ (a) and $10 \mathrm{~K}$ (b) for $\mathrm{MnFe}_{2} \mathrm{O}_{4} / \mathrm{Pt}$ (black), $\mathrm{CoFe}_{2} \mathrm{O}_{4} / \mathrm{Pt}$ (red), and NiFe $\mathrm{O}_{4} / \mathrm{Pt}$ (blue) samples. $\mathrm{XMCD}$ spectra of the $\mathrm{Co} / \mathrm{Pt}$ reference sample (orange) are also shown for comparison. (c) XANES and XMCD spectra at Pt $\mathrm{L}_{2,3}$ edges recorded at $10 \mathrm{~K}$ for the Co/Pt reference sample.

at the $\mathrm{Pt} \mathrm{L}_{3}$ edge on a $\mathrm{Fe}_{3} \mathrm{O}_{4}(38 \mathrm{~nm}) / \mathrm{Pt}(2 \mathrm{~nm})$ sample. $\mathrm{Fe}_{3} \mathrm{O}_{4}(111)$ thin films have been grown by molecular beam epitaxy, ${ }^{18}$ and the Pt layer was grown in the same conditions as those for the ferrite/Pt samples. In Fig. 3, we display XANES and XMCD spectra recorded well below (10 K) and well above $(290 \mathrm{~K})$ the Verwey transition which occurs at $\sim 120 \mathrm{~K}$ in our thin films. ${ }^{34}$ The WL intensity is about 1.35 and is similar to the $\mathrm{Co} / \mathrm{Pt}$ reference sample shown in Fig. 1. Hence, the WL intensity does not indicate $\mathrm{Pt}$ oxidation. Counterintuitively, the XANES spectrum of $\mathrm{Fe}_{3} \mathrm{O}_{4}$ is closer to the $\mathrm{NiFe}_{2} \mathrm{O}_{4}$ one than the $\mathrm{MnFe}_{2} \mathrm{O}_{4}$ and $\mathrm{CoFe}_{2} \mathrm{O}_{4}$ ones.

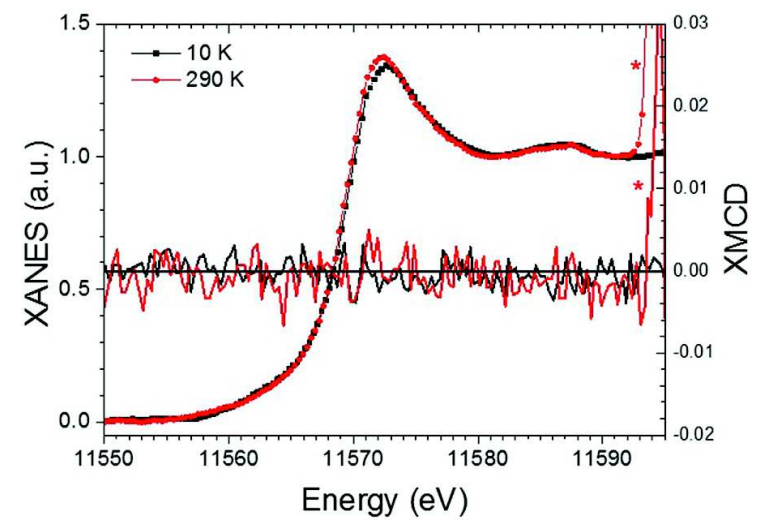

FIG. 3. Normalized $\mathrm{Pt} \mathrm{L}_{3}$ edge XANES and XMCD spectra of the $\mathrm{Fe}_{3} \mathrm{O}_{4} / \mathrm{Pt}$ sample recorded at $10 \mathrm{~K}$ (black) and $290 \mathrm{~K}$ (red). Asterisks point out diffraction peaks.
With $\mathrm{NiFe}_{2} \mathrm{O}_{4}$ having the largest energy gap, this would indicate that different hybridization mechanisms at ferrite/Pt and magnetite/Pt interfaces take place. The main result is that no XMCD signal is observed at the $\mathrm{Pt} \mathrm{L}_{3}$ edge whether below or above the Verwey transition ruling out magnetic proximity effects in both the insulating and conducting phases of $\mathrm{Fe}_{3} \mathrm{O}_{4}$.

These results raise the question of possible induced magnetic moments between a magnetic oxide and a nonmagnetic metal. While there are a large number of reports on induced moments on $4 d$ and $5 d$ elements when in contact with $3 d$ ferromagnetic metals, ${ }^{5-8}$ up to now, most of the ferromagnetic oxide/Pt interfaces in high quality samples as the ones studied here do not show magnetic proximity effects. We give a clear confirmation of this for $\mathrm{Pt}$ interfaced with $\mathrm{MnFe}_{2} \mathrm{O}_{4}, \mathrm{CoFe}_{2} \mathrm{O}_{4}, \mathrm{NiFe}_{2} \mathrm{O}_{4}$, and $\mathrm{Fe}_{3} \mathrm{O}_{4}$. This remains valid at low temperature and independent of the insulating or conducting state of the ferrite.

In conclusion, we have searched for induced magnetic moments at several ferrite/Pt interfaces by XANES and XMCD measurements at the $\mathrm{Pt} \mathrm{L}_{3}$ edge. No XMCD signals as fingerprints of induced magnetic moments in $\mathrm{Pt}$ have been detected for the three different insulating ferrites $\left(\mathrm{MnFe}_{2} \mathrm{O}_{4}\right.$, $\mathrm{CoFe}_{2} \mathrm{O}_{4}$, and $\mathrm{NiFe}_{2} \mathrm{O}_{4}$ ). However, slight changes in XANES spectra and in particular a shift towards lower energies of the WL suggest different hybridization at the ferrite/Pt interfaces that remain to be fully understood. In particular, a clear charge transfer occurs between $\mathrm{Pt}$ and $\mathrm{MnFe}_{2} \mathrm{O}_{4}$ which has 
the lowest energy gap. XMCD measurements were also performed on $\mathrm{Fe}_{3} \mathrm{O}_{4} / \mathrm{Pt}$ below and above the Verwey transition. On either sides of the metal-insulator transition, no induced moment was observed. This suggests that the absence of magnetic proximity effects at ferrite/Pt interfaces is not linked to the insulating character of the ferrites. We hope that our systematic investigation will trigger theoretical studies allowing to settle if the absence of induced magnetic moments at ferrite/Pt interfaces is a general rule and identify the possible role of defects and disorder in establishing magnetic moments or not since anisotropic magnetoresistance effects have been recently observed in the $\mathrm{CoFe}_{2} \mathrm{O}_{4} / \mathrm{Pt}$ bilayer, ${ }^{29}$ suggesting the magnetic proximity effect.

See supplementary material for magnetic characterization of ferrite thin films.

We acknowledge European Synchrotron Radiation Facility support (Project No. HC-1493).

${ }^{1}$ K. Uchida, S. Takahashi, K. Harii, J. Ieda, W. Koshibae, K. Ando, S. Maekawa, and E. Saitoh, "Observation of the spin Seebeck effect," Nature 455, 778 (2008).

${ }^{2}$ K. Uchida, J. Xiao, H. Adachi, J.-I. Ohe, S. Takahashi, J. Ieda, T. Ota, Y. Kajiwara, H. Umezawa, H. Kawai, G. E. W. Bauer, S. Maekawa, and E. Saitoh, "Spin Seebeck insulator," Nat. Mater. 9, 894 (2010).

${ }^{3}$ S. O. Valenzuela and M. Tinkham, "Direct electronic measurement of the spin Hall effect," Nature 442, 176 (2006).

${ }^{4}$ S.-Y. Huang, X. Fan, D. Qu, Y. Chen, W. Wang, J. Wu, T. Chen, J. Xiao, and C. Chien, "Transport magnetic proximity effects in platinum," Phys. Rev. Lett. 109, 107204 (2012)

${ }^{5}$ J. Vogel, A. Fontaine, V. Cros, F. Petroff, J.-P. Kappler, G. Krill, A. Rogalev, and J. Goulon, "Structure and magnetism of Pd in Pd/Fe multilayers studied by x-ray magnetic circular dichroism at the Pd L2, 3 edges," Phys. Rev. B 55, 3663 (1997).

${ }^{6}$ F. Wilhelm, P. Poulopoulos, G. Ceballos, H. Wende, K. Baberschke, P. Srivastava, D. Benea, H. Ebert, M. Angelakeris, N. Flevaris, D. Niarchos, A. Rogalev, and N. B. Brookes, "Layer-resolved magnetic moments in Ni/ Pt multilayers," Phys. Rev. Lett. 85, 413 (2000).

${ }^{7}$ J. Bartolomé, A. Figueroa, L. Garcia, F. Bartolomé, L. Ruiz, J. GonzálezCalbet, F. Petroff, C. Deranlot, F. Wilhelm, A. Rogalev, and N. Brookes, "Perpendicular magnetic anisotropy in Co/Pt granular multilayers," Low Temp. Phys. 38, 835 (2012).

${ }^{8}$ F. Wilhelm, P. Poulopoulos, A. Scherz, H. Wende, K. Baberschke, M. Angelakeris, N. Flevaris, J. Goulon, and A. Rogalev, "Interface magnetism in 3d/5d multilayers probed by X-ray magnetic circular dichroism," Phys. Status Solidi (a) 196, 33 (2003).

${ }^{9}$ S. Geprägs, S. Meyer, S. Altmannshofer, M. Opel, F. Wilhelm, A. Rogalev, R. Gross, and S. T. Goennenwein, "Investigation of induced Pt magnetic polarization in Pt/Y3Fe5O12 bilayers," Appl. Phys. Lett. 101, 262407 (2012).

${ }^{10}$ Y. Lu, Y. Choi, C. Ortega, X. Cheng, J. Cai, S. Huang, L. Sun, and C. Chien, "Pt magnetic polarization on $\mathrm{Y} 3 \mathrm{Fe} 5 \mathrm{O} 12$ and magnetotransport characteristics," Phys. Rev. Lett. 110, 147207 (2013).

${ }^{11}$ S. Geprägs, S. T. B. Goennenwein, M. Schneider, F. Wilhelm, K. Ollefs, A. Rogalev, M. Opel, and R. Gross, "Comment on Pt magnetic polarization on Y3Fe5O12 and magnetotransport characteristics," preprint arXiv:1307.4869 (2013).

${ }^{12}$ O. d'Allivy Kelly, M. M. Collet, E. Jacquet, R. Mattana, F. Petroff, P. Bortolloti, V. Cros, A. Anane, F. Wilhelm, K. Ollefs, and A. Rogalev, "Magnetic proximity effect free spin Hall magnetoresistance in YIG/Pd films," SPIN 07, 1740005 (2017).

${ }^{13}$ D. Meier, T. Kuschel, L. Shen, A. Gupta, T. Kikkawa, K.-I. Uchida, E. Saitoh, J.-M. Schmalhorst, and G. Reiss, "Thermally driven spin and charge currents in thin $\mathrm{NiFe}_{2} \mathrm{O}_{4} / \mathrm{Pt}$ films," Phys. Rev. B 87, 054421 (2013).

${ }^{14}$ K.-I. Uchida, T. Nonaka, T. Ota, and E. Saitoh, "Longitudinal spinSeebeck effect in sintered polycrystalline $(\mathrm{Mn}, \mathrm{Zn}) \mathrm{Fe}_{2} \mathrm{O}_{4}$, , Appl. Phys. Lett. 97, 262504 (2010).
${ }^{15}$ D. Meier, D. Reinhardt, M. van Straaten, C. Klewe, M. Althammer, M. Schreier, S. T. B. Goennenwein, A. Gupta, M. Schmid, C. H. Back, J.-M. Schmalhorst, T. Kuschel, and G. Reiss, "Longitudinal spin Seebeck effect contribution in transverse spin Seebeck effect experiments in Pt/YIG and Pt/NFO," Nat. Commun. 6, 8211 (2015).

${ }^{16}$ T. Niizeki, T. Kikkawa, K.-I. Uchida, M. Oka, K. Z. Suzuki, H. Yanagihara, E. Kita, and E. Saitoh, "Observation of longitudinal spinSeebeck effect in cobalt-ferrite epitaxial thin films," AIP Adv. 5, 053603 (2015).

${ }^{17}$ M. Isasa, S. Vélez, E. Sagasta, A. Bedoya-Pinto, N. Dix, F. Sánchez, L. E. Hueso, J. Fontcuberta, and F. Casanova, "Spin hall magnetoresistance as a probe for surface magnetization in $\mathrm{Pt} / \mathrm{CoFe} 2 \mathrm{O} 4$ bilayers," Phys. Rev. Appl. 6, 034007 (2016).

${ }^{18}$ J.-B. Moussy, "From epitaxial growth of ferrite thin films to spin-polarized tunneling,” J. Phys. D: Appl. Phys. 46, 143001 (2013).

${ }^{19}$ S. Matzen, J.-B. Moussy, R. Mattana, K. Bouzehouane, C. Deranlot, F. Petroff, J. C. Cezar, M.-A. Arrio, P. Sainctavit, C. Gatel, B. WarotFonrose, and Y. Zheng, "Epitaxial growth and ferrimagnetic behavior of $\mathrm{MnFe}_{2} \mathrm{O}_{4}$ (111) ultrathin layers for room-temperature spin filtering," Phys. Rev. B 83, 184402 (2011).

${ }^{20} \mathrm{~A}$. Rogalev and F. Wilhelm, "Magnetic circular dichroism in the hard Xray range,” Phys. Met. Metallogr. 116, 1285 (2015).

${ }^{21}$ J. Bartolomé, F. Bartolomé, L. Garcia, E. Roduner, Y. Akdogan, F. Wilhelm, and A. Rogalev, "Magnetization of Pt13 clusters supported in a NaY zeolite: A XANES and XMCD study," Phys. Rev. B 80, 014404 (2009).

${ }^{22}$ A. Kolobov, F. Wilhelm, A. Rogalev, T. Shima, and J. Tominaga, "Thermal decomposition of sputtered thin PtOx layers used in superresolution optical disks," Appl. Phys. Lett. 86, 121909 (2005).

${ }^{23}$ D. Friebel, D. J. Miller, C. P. O'Grady, T. Anniyev, J. Bargar, U. Bergmann, H. Ogasawara, K. T. Wikfeldt, L. G. Pettersson, and A. Nilsson, "In situ X-ray probing reveals fingerprints of surface platinum oxide,” Phys. Chem. Chem. Phys. 13, 262-266 (2011).

${ }^{24}$ J. Ramallo-López, F. Requejo, A. Craievich, J. Wei, M. Avalos-Borja, and E. Iglesia, "Complementary methods for cluster size distribution measurements: Supported platinum nanoclusters in methane reforming catalysts," J. Mol. Catal. A: Chem. 228, 299 (2005).

${ }^{25}$ A. I. Figueroa, J. Bartolomé, L. M. García, F. Bartolomé, O. Bunău, J. Stankiewicz, L. Ruiz, J. M. González-Calbet, F. Petroff, C. Deranlot, S. Pascarelli, P. Bencok, N. B. Brookes, F. Wilhelm, A. Smekhova, and A. Rogalev, "Structural and magnetic properties of granular Co-Pt multilayers with perpendicular magnetic anisotropy," Phys. Rev. B 90, 174421 (2014).

${ }^{26}$ Z. Szotek, W. Temmerman, D. Ködderitzsch, A. Svane, L. Petit, and H. Winter, "Electronic structures of normal and inverse spinel ferrites from first principles," Phys. Rev. B 74, 174431 (2006).

${ }^{27}$ M. Valvidares, N. Dix, M. Isasa, K. Ollefs, F. Wilhelm, A. Rogalev, F. Sánchez, E. Pellegrin, A. Bedoya-Pinto, P. Gargiani, L. E. Hueso, F. Casanova, and J. Fontcuberta, "Absence of magnetic proximity effects in magnetoresistive Pt/CoFe ${ }_{2} \mathrm{O}_{4}$ hybrid interfaces," Phys. Rev. B 93, 214415 (2016).

${ }^{28}$ T. Kuschel, C. Klewe, J.-M. Schmalhorst, F. Bertram, O. Kuschel, T. Schemme, J. Wollschläger, S. Francoual, J. Strempfer, A. Gupta, M. Meinert, G. Götz, D. Meier, and G. Reiss, "Static magnetic proximity effect in $\mathrm{Pt} / \mathrm{NiFe}_{2} \mathrm{O}_{4}$ and $\mathrm{Pt} / \mathrm{Fe}$ bilayers investigated by $\mathrm{X}$-ray resonant magnetic reflectivity," Phys. Rev. Lett. 115, 097401 (2015).

${ }^{29}$ W. Amamou, I. V. Pinchuk, A. Hanks, R. Williams, N. Antolin, A. Goad, D. J. O'Hara, A. S. Ahmed, W. Windl, D. W. McComb, and R. K. Kawakami, "Magnetic proximity effect in $\mathrm{Pt} / \mathrm{CoFe}_{2} \mathrm{O}_{4}$ bilayers," e-print arXiv: 1706.08473 .

${ }^{30}$ B. T. Thole, P. Carra, F. Sette, and G. van der Laan, "X-ray circular dichroism as a probe of orbital magnetization," Phys. Rev. Lett. 68, 1943 (1992).

${ }^{31}$ P. Carra, B. T. Thole, M. Altarelli, and X.-D. Wang, "X-ray circular dichroism and local magnetic fields,” Phys. Rev. Lett. 70, 694 (1993).

${ }^{32}$ F. Wilhelm, P. Poulopoulos, H. Wende, A. Scherz, K. Baberschke, M. Angelakeris, N. K. Flevaris, and A. Rogalev, "Systematics of the induced magnetic moments in 5d layers and the violation of the third Hund's rule," Phys. Rev. Lett. 87, 207202 (2001).

${ }^{33} \mathrm{E}$. Verwey, "Electronic conduction of magnetite $\left(\mathrm{Fe}_{3} \mathrm{O}_{4}\right)$ and its transition point at low temperatures," Nature 144, 327-328 (1939).

${ }^{34}$ J.-B. Moussy, S. Gota, A. Bataille, M.-J. Guittet, M. Gautier-Soyer, F. Delille, B. Dieny, F. Ott, T. D. Doan, P. Warin, P. Bayle-Guillemaud, C. Gatel, and E. Snoeck, "Thickness dependence of anomalous magnetic behavior in epitaxial $\mathrm{Fe}_{3} \mathrm{O}_{4}(111)$ thin films: Effect of density of antiphase boundaries," Phys. Rev. B 70, 174448 (2004). 